\title{
Two new families of the Pezizales: Karstenellaceae and Pseudorhizinaceae
}

\author{
Harri Harmaja \\ Department of Botany, University of Helsinki, SF-00170 Helsinki, Finland
}

\begin{abstract}
Harmaja, H. 1974: Two new families of the Pezizales: Karstenellaceae and Pseudorhizinaceae. - Karstenia 14: 109-112.

The author considers especially the sporal, anatomical and cytological characters of the genera Karstenella Harmaja and Pseudorhizina Jach. to warrant the establishment of a new monotypic family for each: Karstenellaceae Harmaja and Pseudorhizinaceae Harmaja. Certain characters relevant to the family level taxonomy have been observed by the author in both genera. Features apparently diagnostic of the family Karstenellaceae are the presence of two nuclei in the spores, the lack of a cyanophilic perispore in all stages of spore development, the simple structure of the excipulum which is exclusively composed of textura intricata, and the subicular characters. The genera of the Pezizales with tetranucleate spores are considered to form three different families on the basis of both sporal and anatomical differences: Helvellaceae Dum., Pseudorhizinaceae and Rhizinaceae Bon. The lack of a cyanophilic perispore in the mature spores and the simple structure and thick-walled hyphae of the excipulum are important distinguishing features of the family Pseudorhizinaceae. Comparisons are given between Pseudorhizinaceae and the two other families.
\end{abstract}

\section{Karstenellaceae Harmaja}

The description of the genus Karstenella Harmaja was based on the new species $K$. vernalis Harmaja described in the same paper (Harmaja 1969b). Even then I noted that the genus possessed such characters that it was impossible to place it in any known family of the Pezizales. Prof. Dr. Richard P. Korf, on borrowing the type of $K$. vernalis, found that the spores contained two nuclei each, which is a unique number in the order Pezizales. He therefore agreed that either a new tribe or even a new family should be established for this genus (Korf 1972 and in litt.). In one of my letters to Prof. Korf I suggested that the genus might possibly be related to Pyronema Carus or Octospora Gray. Korf (1972 and in litt.) thought that Pyronema was not a bad guess, and in his valuable publication of 1972 the new tribe Karstenelleae Korf was established in the subfamily Pyronematoideae of the family Pyronemataceae Corda. In that paper he writes that Karstenella is »clearly a most unusual member of the order, and a monotypic family to accommodate it would not be unreasonable». Considering my original opinion, and as I also regard Prof. Korf's concept of the family Pyronemataceae too wide, e.g. in view of EcKBLAD's study (1968) the excipular anatomy appears to deserve more emphasis, my own conclusion regarding Karstenella agrees with this alternative discussed by him. Accordingly I propose a new monotypic family, Karstenellaceae, for this genus, in the suborder Pezizineae.

In the following those characters of Kars- 
tenellaceae will be cited which appear to have most taxonomic significance at the family level; for a detailed description of the features of Karstenella the original description (Harmaja 1969b) should be consulted.

1) The ascocarp is flat, fairly small, very thin as compared with its diameter and appressed to the substrate throughout. 2) A subiculum of whitish hyphae is present. 3) Red pigment is present in the ascocarp (in the contents of the paraphyses). 4) The spores are binucleate. According to present knowledge (cf. Korf 1972) this is the only case in the Pezizales. 5) The spores lack a cyanophilic perispore-periplasm during their whole development, i.e. belong to the Morchella type (Harmaja 1974b). 6) The spores are completely smooth during their whole development, also with an oil immersion lens. 7) The spores are hyaline. 8) The spore contents are \pm homogeneous, lacking oil drops. 9) De Bary bubbles are lacking in the spores at all stages in heated cotton blue mounts. 10) The asci and the spores within a single ascocarp are at different stages of development. 11) The asci have inamyloid walls. 12) The contents of the paraphyses show no green reaction with Melzer's reagent. 13) The excipulum is composed throughout of textura intricata with narrow and thinwalled hyphae. 14) Specialized hairs are lacking. 15) The subicular hyphae have thick, papillose, and strongly cyanophilic walls.

Karstenellaceae Harmaja, n. famil. - $F a$ milia ex ordine Pezizales, subordine Pezizineae. Ascocarpus tenuissimus, applanatus, colore aurantiaco, ad subiculum e hyphis crassitunicatis, papillatis et cyanophilibus: Excipulum omnino e textura intricata. Asci parietibus ad apicibus haud manifeste incrassatis, iodo haud caerulescentes. Sporae hyalinae, satis tenuitunicatae, eguttulatae, sine vacuolis gaseosis, cum duobus nucleis. Paraphyses intus iodo haud virides. - Type: Karstenella Harmaja.

\section{Pseudorhizinaceae Harmaja}

The genus Pseudorhizina Jachevsky (Helvellella Imai, Ochromitra Vel., Gyromitrodes Vas.), if recognized at all, was long regarded as monotypic with Helvella sphaerospora Peck as its only species. However, in a recent paper (HARMAJA 1973) it was demonstrated that the genus is valid and natural, and it was amended to include two species: Helvella californica Phill. and the type species mentioned above. The paper gave both the differences between the genera Pseudorhizina and Gyromitra and those between the two Pseudorhizina species. Two additional characters common to both species will be reported here together with the observations justifying the establishment of a separate family to accommodate Pseudorhizina.

Firstly, I observed that the spores of both $P$. sphaerospora and $P$. californica (part of the holotype at Kew, K, studied) belong to the Otidea type (Harmaja 1974b), i.e., they possess a strongly cyanophilic perisporeperiplasm complex when immature (excluding the very youngest stages when only a cyanophobic true wall and moderately cyanophilic contents are observed), but lack such a coating when mature. In my earlier stu- dies (Harmaja 1969a, 1973) I had failed to observe the presence of this layer during the immature stages of the spores. The cyanophilic layer is very thin, ca. $0.2-0.3 \mu \mathrm{m}$ when thickest, smooth or slightly uneven, its formation beginning evenly all over the spore wall. In young spores in this genus (in $P$. sphaerospora) the perispore is very occasionally seen to be partly detached from the spore wall proper, so that its existence cannot be in doubt.

Secondly, the spores of both species of Pseudorhizina were found to be tetranucleate, which confirms the affinity of this genus to Helvella and Gyromitra. The nuclei are carminophobic in mature spores, but in the immature ones they stain to some extent, so that the presence of four nuclei in the middle of the spore could be demonstrated. The median position of the nuclei was exactly as in the young spores of the certainly tetranucleate species Helvella acetabulum, studied for control. The large central oil drop developing later in that species forces the nuclei to both ends of the spore, pressing them against the spore wall. Staining the Pseudorhizina spores by the usual acetocar- 
mine + boiling method gave poor results, but preceding treatment with $\mathrm{KOH}$ (see Harmaja 1974c) considerably improved the absorption of the dye in this genus, too (however, the nuclei in the mature spores continued to be carminophobic).

Details about the characters of the species of Pseudorhizina as well as references to further literature may be found in Harmaja 1973 , so in the following I will restrict the discussion to the characters which I consider diagnostic at the family level, and will give the features which separate the proposed monotypic family Pseudorhizinaceae from the two other families (in my sense) of the Pezizales with tetranucleate spores, viz. $\mathrm{Hel}$ vellaceae Dum. (with Helvella only; see Harmaja 1974a) and Rhizinaceae Bon. (with Gyromitra and Rhizina; see Harmaja 1969a and 1973). Some of these differences have not been reported before.

A. Differences from Helvellaceae. 1) The stipe very often stains red (see Harmaja 1973) in Pseudorhizina but never does so in the Helvellaceae. 2) The mature spores of Pseudorhizina are devoid of a cyanophilic perispore-periplasm complex, as already reported (Harmaja 1969a), while such a complex appears to be present in the mature spores of Helvellaceae, though not all the species have yet been studied by me. In the Helvellaceae (and elsewhere) it seems to be generally believed that a perisporial sheath (often regarded as »exosporium») is present only when the spore is seen to be ornamented, but in many genera (Harmaja 1969a, 1973: 52, 1974c, 1974b) I have also observed a smooth perispore-periplasm complex in the mature spores. It is indeed more logical to suppose that both ornamented and smooth perisporial sheaths can exist. The spores of Pseudorhizina thus belong to the Otidea type, or temporarily perisporous type, according to the nomenclature of HARMAJA (1974b). As the contents of the mature spores in Pseudorhizina are cyanophobic, the spores remain completely hyaline without any tinge of blue even after repeated boiling in cotton blue. In contrast, the spores of the Helvellaceae assume a distinct blue colour (it remains, however, to be ascertained whether this blue is simply due to the bluestaining perispore-periplasm or if in addition the contents of these ripe spores are also cyanophilic; the oil clrops are, as usual, cyanophobic). 3) The nuclei of ripe spores from dried specimens are carminophobic in Pseudorhizina (even after repeated boiling), while in the Helvellaceae they are carminophilic. 4) A certain proportion of mature spores of Pseudorhizina (though it is very small in $P$. californica) contain in heated cotton blue one de Bary bubble each, while these are completely lacking in the Helvellaceae. 5) The hyphae of the excipulum (those of the subhymenium excluded) are thickwalled in Pseudorhizina, the thickness varying between ca. 0.7 and $2.0 \mu \mathrm{m}$. This probably accounts for the poor reviving capacity of the hyphae of dried specimens, at least in heated cotton blue, where they remain collapsed even after repeated boiling. The hyphae of the Helvellaceae have distinctly thinner walls and revive easily when prepared for a microscopic mount. 6) As is already known, the construction of the excipuli differs, that of Pseudorhizina being composed of textura intricata throughout, while that of the Helvellaceae has an ental part of $t$. intricata and a distinct ectal layer of $t$. prismatica to $t$. angularis.

B. Differences from Rhizinaceae (cf. also Harmaja 1973). 1) The same as the first difference from the Helvellaceae (see above). 2) Exactly the same as the second difference from the Helvellaceae (cf. also Harmaja 1969a). The Rhizinaceae spores also belong to the Peziza type, or the persistently perisporous type (Harmaja 1974b). Even the unripe spores show a difference, since when discernible the perispore-periplasm in Pseudorhizina is always equally thick all around the spore, while in the Rhizinaceae it first forms as caps at the spore ends. 3) As the fourth difference from the Helvellaceae (note, however, the exception concerning Gyromitra ambigua, mentioned on p. 125 in Harmaja 1974b). 4) As the fifth difference from the Helvellaceae. 5) The cyanophilic septal collars are different (Harmaja 1973: 50, 55). 6) The responses of the paraphysis pigments to $\mathrm{KOH}$ are different (cf. Harmaja 1973: 50).

Pseudorhizinaceae Harmaja, n. famil. Familia ex ordine Pezizales, subordine Pezizineae. Ascocarpus pileatus. Excipulum omnino $e$ textura intricata $\epsilon$ hyphis parietibus incrassatis. Asci parietibus ad apicibus haud 
manifeste incrassatis, iodo haud caerulescentes. Sporae tetranucleatae, guttulatae, cum perispora-periplasma cyanophila quam immaturi, sine ea et laeves quam maturi. - Typus: Pseudorhizina Jach.
Acknowledgements. - My sincere thanks are due to the Director of the Royal Botanic Gardens and Herbarium at Kew (K) for arranging the loan of a fragment of the holotype of Helvella californica.

\section{REFERENCES}

ECKBLAD, F.-E. 1968: The genera of the operculate Discomycetes. A re-evaluation of their taxonomy, phylogeny and nomenclature. N. Mag. Bot. 15: 1-191.

HaRmajA, H. 1969a: A wider and more natural concept of the genus Gyromitra Fr. Karstenia 9: 9-12.

- 1969b: Karstenella vernalis Harmaja, a new genus and species of Discomycetes from Finland. - Karstenia 9: 20-22.

- 1973: Amendments of the limits of the genera Gyromitra and Pseudorhizina, with the description of a new species, Gyromitra montana. - Karstenia 13: 48-58.

- 1974a: Notes on the genus Helvella, including the merging of the genus Wynnella. - Karstenia 14: 102-104.

- 1974b: Observations on the presence of a cyanophilic perispore in the spores of the Pezizales. - Karstenia 14: 123-125.

- 1974c: The generic limit between Otidea and Tarzetta (Pustularia auct.). - Karstenia 14: 138-142.

KORF, R.P. 1972: Synoptic key to the genera of the Pezizales. - Mycologia 64: 937-994. 